\title{
PROSPEK DAN RANTAI PASOK BUNGA MELATI PUTIH (Jasminum sambac) DI KABUPATEN BANJAR PROVINSI KALIMANTAN SELATAN
}

\author{
(Prospects and Supply Chain Of White Jasmine Flower (Jasminum Sambac) In Banjar Regency \\ South Kalimantan Province)
}

Fitri Mahyudi dan Husinsyah

Program Studi Agribisnis Fakultas Pertanian

Universitas Achmad Yani Banjarmasin

Penulis koresponden: fitri.mahyudi@yahoo.co.id;;

Article Submitted: $10-11-2020$

Article Accepted: 14-12-2020

\begin{abstract}
The study aims to determine the flow of products, finance, information, analyze marketing efficiency in the chain supply of Jasminum sambac in Banjar Regency and analyze the differences Jasminum sambac marketing efficiency in the supply chain between Martapura District and Banjar District. This research was conducted in Oktober 2020. The research was carried out in Martapura District and Banjar District because were the largest centers of jasmine production in Banjar Regency. Determination of farmer respondents was carried out using the Simple Random Sampling method using the Slovin formula, namely 26 respondents in Karang Intan District and 31 respondents in Karang Intan District. Determination of off-farm respondents using the Snowball Sampling method, namely 31 farmers, 9 collectors, 5 wholesaler respondents, and 12 retail respondents. The analytical method used is descriptive, marketing efficiency analysis method, and using a different test independent sample t-test. The supply chain pattern of jasmine flowers in Martapura and Karang Intan Districts is pattern 1, pattern 2, and pattern 3. The largest value of marketing margin and marketing share in Martapura District was Rp 12,462 and $65.87 \%$. The value of the marketing margin and marketing share of Karang Intan District was IDR 13,582 and 69.88\%, respectively. Different test results Independent sample ttest on marketing margin, the value of Sig. 2 tailed amounted to 0.246. The results of different test Independent samples t-test on the marketing share obtained the Sig. 2 tailed amounted to 0.221. These results show a number> 0.05, that no significant difference in marketing efficiency between Martapura and Banjar Districts.
\end{abstract}

Keywords: jasmine, marketing efficiency, supply chain

\section{PENDAHULUAN}

Tanaman hortikultura bunga hias yang banyak di budidayakan di Indonesia salah satunya adalah Bunga melati. Bunga melati yang di budidayakan umumnya ada 2 jenis melati putih, yaitu bunga melati erwarna putih susu (Jasminum sambac) dan bunga melati berjenis gambir (Jasminum officinale). Pada bidang agribisnis hortikultura terutama jenis bunga hias potensi bunga melati putih cukup menjanjikan dengan potensi produksi rata-rata perharinya 16,2 $\mathrm{kg}$ (antara 5-20 kg). Provinsi Jawa Tengah terutama Kabupaten Tegal, Pekalongan dan Purbalingga adalah daerah pemasok bunga melati putih.Sentra melati putih di Indonesia terdapat di Provinsi Jawa Tengah (Kab.Tegal, Kab. Pemalang, Kab. Pekalongan, Kab. Banjar dan Purbalingga), sedangkan di Provinsi Kalimantan Selatan juga memiliki sentra 
wilayah produksi bunga dengan jenis macam bunga melati putih putih, kenanga kuning dan mawar berwarna merah terutama di wilayah Desa Bincau, Desa Labuan Tabu di Kecamatan Martapura yang berjarak 5 kilometer dari ibu kota kabupaten dan dan Daerah penghasil bunga terdapat di Kecamatan Martapura dan Desa Karang Intan, Desa Jingah Habang, Desa Pandak Daun di kecamatan Karang Intan

$$
\text { Pengembangan Potensi cukup }
$$

besar dari bunga hias melati putih, kenanga kuning dan mawar merah di lima desa pada Kabupaten Banjar. Permintaan bunga dipengaruhi oleh adat istiadat dan pranata sosial warga banjar seperti penggunaan melati putih untuk riasan pengantin dan ritual adat lainnya. sehingga bunga melati putih putih sangat layak dikembangkan dan memberikan peluang usaha kepada warga desa dan dapat menyerap tenaga kerja di lokasi tersebut. Pada Tabel 1 disajikan luasan panen melati putih dan jumlah produksi melati putih di Kabupaten Banjar.

Tabel 1. Luasan Panen Melati Putih dan Jumlah Produksi Melati Putih Di Kabupaten Banjar selama 3 Tahun Terakhir (2017 - 2019).

\begin{tabular}{cccc}
\hline \multirow{2}{*}{ Keterangan } & \multicolumn{3}{c}{ Tahun } \\
\cline { 2 - 4 } & 2017 & 2018 & 2019 \\
\hline Luas Panen $\left(\mathrm{m}^{2}\right)$ & 249.860 & 162.700 & 184.890 \\
Produksi (tangkai) & 785.680 & 971.000 & 756.160 \\
\hline
\end{tabular}

Sumber : BPS Kabupaten Banjar Dalam Angka 2018-2020

Dari Tabel 1 terlihat luas panen melati putih di Kabupaten Banjar pada tahun 2017 seluas $249.860 \mathrm{~m} 2$ dan menurun pada tahun 2019 yaitu hanya seluas $184.890 \mathrm{~m} 2$. Untuk poroduksi bunga melati putih pada tahun 2017 sebanyak 785.680 tangkai dan pada tahun 2019 menurun menjadi 756.160 tangkai.

Dari uraian tersebut penelitian ini bertujuan untuk (1) Mengetahui proses alur produk, proses jalur keuangan dan jalur informasi bunga melati putih pada 5 desa di Kabupaten Banjar (2) Mengidentifikasi efisiensi pemasaran bunga melati putih pada rantai pasok di 5 desa pada Kabupaten Banjar (3) Mengidentifikasi perbandingan jalur rantai pemasaran pada Kecamatan Martapura dan Kecamatan Karang Intan

\section{METODOLOGI PENELITIAN}

Pada bulan Oktober sampai dengan November 2020 penelitian rantai pasok ini dilaksanakan di Kecamatan
Martapura yaitu Desa Bincau dan Desa Kecamatan Karang Intan yaitu Desa Jingah Habang Kabupaten Banjar. Penentuan lokasi penelitian berdasarkan pertimbangan bahwa di Kecamatan Martapura dan Kecamatan Karang Intan merupakan sentra produksi bunga melati putih terbesar di Kabupaten Banjar dan pemasok utama produksi bunga melati putih di Kalimantan Selatan. Identifikasi penelitian menggunakan jenis survei yaitu dengan wawancara kepetani sebagai sampel penelitian menggunakan quisioner lengkap baik identifikasi usaha, margin dan efisiensi usaha melati.

Responden petani dipilih menggunakan metode Simple Random Sampling dengan menggunakan rumus Slovin, yaitu 26 responen di Kecamatan Karang Intan dan 31 responden di Kecamatan Martapura. Penentuan responden off farm menggunakan metode Snowball Sampling yaitu 31 
petani melati putih, 9 responden pengumpul, 5 responden pedagang besar dan 12 responden pengecer.

Rantai pasok jenis bunga melati putih di Kabupaten Banjar menggunakan metode analisis efisiensi dari pemasaran bunga melati putih. Efisiensi dari pemasaran diketahui yaitu dengan menggunakan perhitungan Microsoft Excel pada windows dan

aplikasi SPSS untuk menganalisis nilai dari marjin pemasaran bunga melati putih dan share pemasaran.

Rumus mengidentifikasi margin pemasaran bunga melati putih pada pola saluran pemasaran (Daniel, 2020).

Keterangan:

$$
\mathrm{M}_{\mathrm{BM}}=\mathrm{Hk}_{\mathrm{BM}}-\mathrm{Hp}_{\mathrm{BM}}
$$

$\mathrm{M}_{\mathrm{BM}}=$ Marjin dari Pemasaran bunga melati putih

$\mathrm{Hk}_{\mathrm{BM}}=$ Harga pada tingkat Konsumen bunga melati putih

$\mathrm{Hp}_{\mathrm{BM}}=$ Harga pada tingkat Produsen bunga melati putih

Hanafiah dan Saefuddin (dalam Harifuddin,2011) menggunakan perhitungan untuk menghitung persentase marjin yaitu.

$$
\% \mathrm{M}_{\mathrm{BM}}=\frac{\mathrm{HE}_{\mathrm{BM}}}{\mathrm{M}_{\mathrm{BM}}} \times 100 \%
$$

Keterangan:

$\% \mathrm{M}_{\mathrm{BM}}=$ Persentase dari Marjin bunga melati putih

$\mathrm{HE}_{\mathrm{BM}}=$ Harga pada tingkat Eceran bunga melati putih

$\mathrm{M}_{\mathrm{BM}}=$ Marjin bunga melati putih

Kotler (2008) menjelaskan cara perhitungan farmer share bunga melati putih yaitu :

$$
\mathrm{FS}_{\mathrm{BM}}=\frac{\mathrm{Pf}_{\mathrm{BM}}}{\operatorname{Pr}_{\mathrm{BM}}} \times 100 \%
$$

Keterangan:

$\mathrm{FS}_{\mathrm{BM}}=$ Persentase dari harga yang diterima petani bunga melati putih

$\mathrm{Pf}_{\mathrm{BM}}=$ Harga yang didapat petani bunga melati putih
$\operatorname{Pr}_{\mathrm{BM}}=$ Harga yang didapat pengecer bunga melati putih

Rumus dari Soekartawi (2002) yaitu melakukan perhitungan tingkat efisiensi dari pemasaran bunga melati putih pada bagianbagian lembaga/jalur pemasaran, yaitu :

$$
\operatorname{Eps}_{\mathrm{BM}}=\frac{\mathrm{Bp}}{\mathrm{HE}_{\mathrm{BM}}} \times 100 \%
$$

Keterangan:

$\operatorname{Eps}_{\mathrm{BM}}=$ Efesiensi dari Pemasaran bunga melati putih

$\mathrm{Bp}_{\mathrm{BM}}=$ Biaya dari Pemasaran bunga melati putih

$\mathrm{HE}_{\mathrm{BM}}=$ Harga di tingkat Eceran bunga melati putih

Kriteria : - Eps $_{\mathrm{BM}}<5 \%$ Efisien Pemasaran bunga melati putih

- Eps $_{\text {BM }}>5 \%$ Tidak Efisien Pemasaran bunga melati putih

Perhitungan uji beda parametik yaitu

uji beda Independent Sample t-test

dipakai untuk mengidentifikasi perbandingan jalur rantai pasok pada masing-masing wilayah.

Hipotesis yang akan diuji adalah:

H0: $\mu_{1}-\mu_{2}=0$, efisiensi rantai pasok pada

Kecamatan Martapura dan Kecamatan

Karang Intan di Kabupaten Banjar tidak terdapat perbedaan.

$\mathrm{H} 1: \mu 1-\mu 2 \neq 0$, efisiensi rantai pasok pada

Kecamatan Martapura dan Kecamatan

Karang Intan di Kabupaten Banjar terdapat perbedaan .

A d a p u $\mathrm{kr}$ i t e ri a pengambilan keputusan adalah sebagai berikut: Ho"ditolak dan $\mathrm{H} 1$ diterima jika Sig. 2 tailed $\leq 0,05 . \mathrm{H}_{\mathrm{o}}$ diterima dan $\mathrm{H}_{1}$ ditolakjika Sig. 2 tailed $>0,05$

\section{HASIL DAN PEMBAHASAN}

\section{Karakteristik Responden}

Pelaku rantai pasok bunga melati putih di Kabupaten Banjar meliputi petani, pengepul, pedagang besar dan pengecer. Jumlah responden petani sebanyak 31 
orang petani yang terdiri dari 25 responden dengan usia produktif dan 6 non produktif, responden pengepul sebanyak 9 orang yang terdiri dari 7 responden dengan usia produktif dan 2 non produktif, responden pedagang besar sebanyak 5 yang keseluruhan dalam usia produktif dan responden pengecer sebanyak 12 yang keseluruhan dalam usia produktif. Usia produktif berada di umur 15 - 55 tahun sehingga dapat lebih dinamis dalam inovasi dan teknologi.

\section{Aktivitas Pelaku Rantai Pasok Bunga Melati putih}

Aktivitas pelaku pemasaran bunga melati putih di Kabupaten Banjar meliputi aktivitas fisik, fasilitas dan pertukaran.

\section{Petani}

Aktivitas fisik petani bunga melati putih adalah budidaya dan pemanenan. Budidaya dilakukan selama masa periode bunga melati putih, yaitu $3-5$ tahun dengan umur pertama kali panen adalah 8 bulan. Produksi rata - rata yang dihasilkan petani bunga melati putih adalah $532 \mathrm{~kg} / \mathrm{bulan} / \mathrm{ha}$. Aktivitas pertukaran yang dilakukan petani bunga melati putih adalah penjualan dan pembelian. Petani menjual hasil produksi kepada pengepul. Jumlah produksi bunga melati putih rata rata yang dijual petani adalah 532 $\mathrm{kg} / \mathrm{bulan} / \mathrm{ha}$ dengan harga jual rata - rata yaitu Rp 6.500/gelas atau 53.500/kg. Penggunaan gelas dipakai sebagai takaran penjualan melati putih oleh petani melati putih di Kabupaten Banjar

\section{Pengepul}

Aktivitas fisik yang dilakukan pengepul bunga melati putih adalah penyimpanan. Bunga melati putih yang telah didapatkan dari petani disimpan terlebih dahulu sebelum dikirim kepada pedagang besar dan pengecer. Aktivitas pertukaran yang dilakukan pengepul adalah pembelian dan penjualan. Pembelian yang dilakukan pengepul adalah dengan membeli bunga melati putih dari petani dengan cara langsung mendatangi petani dengan harga beli dari petani yaitu $53.500 / \mathrm{kg}$. Jumlah produksi rata - rata yang dijual pengepul adalah $467 \mathrm{~kg} / \mathrm{bulan} / \mathrm{musim}$ dengan harga jual rata-rata Rp 55.500/kg

\section{Pedagang Besar}

Aktivitas fisik pedagang besar bunga melati putih adalah penyimpanan dan pengangkutan. Aktivitas fasilitas pedagang besar bunga melati putih adalah sortasi dan grading. Sortasi dilakukan dengan membedakan bunga melati putih yang layak dan tidak layak untuk dijual. Penjualan oleh pedagang besar dilakukan dengan menjual bunga melati putih kepada konsumen. Pedagang besar membeli bunga melati putih dari pengepul dengan cara langsung mendatangi pengepul atau didatangi oleh pengepul. Jumlah produksi rata - rata yang dibeli oleh pedagang besar dari pengepul adalah $445 \mathrm{~kg} / \mathrm{bulan} / \mathrm{ha}$, dengan harga beli rata - rata sebesar Rp 58.500/kg.

\section{Pengecer}

Aktivitas fisik pengecer bunga melati putih adalah penyimpanan. Aktivitas pertukaran adalah penjualan dan pembelian. Penjualan yang dilakukan oleh pengecer mempunyai target konsumen masyarakat yang membutuhkan bunga melati putih untuk kebutuhan. Pembelian bunga melati putih dilakukan dengan cara pengepul mengantarkan bunga melati putih kepada pengecer. Jumlah produksi rata - rata bunga melati putih yang dibeli pengecer yaitu 430 $\mathrm{kg} / \mathrm{bulan} / \mathrm{ha}$ dengan harga beli rata - rata $\mathrm{d}$ ari pengepul sebesar Rp 60.500/kg.

\section{Konsumen}

Aktivitas pertukaran yang dilakukan konsumen adalah pembelian. Pembelian dilakukan dengan membeli bunga melati putih dari pedagang besar dan pengecer. Bunga melati putih yang dibeli dipergunakan untuk kebutuhan ritual, wedding organizer dan diolah menjadi produk lain. Jumlah produksi rata - rata bunga melati putih yang dibeli 


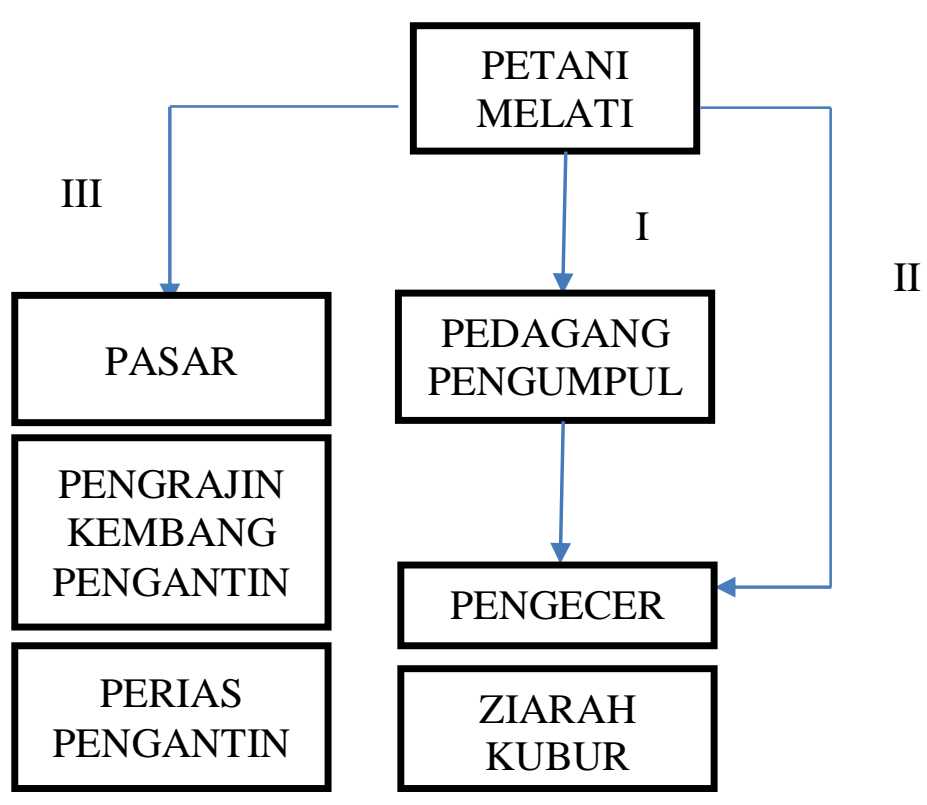

Gambar 1. Analisis Rantai Pasok Komoditas Bunga Melati putih

\section{Aliran Produk}

Pola aliran produk komoditas bunga melati putih bergerak dari petani sampai kepada konsumen. Hal ini sesuai dengan pendapat Yuniar (2012) yang menyatakan bahwa arus barang berjalan dari bagian awal/hulu yaitu pihak petani atau produsen kebagian akhir/hilir pihak konsumen

\section{Aliran Keuangan}

Aliran keuangan komoditas bunga melati putih bergerak dari konsumen menuju ke petani. Menurut Widisatriani (2015) dan Renaldi, dkk (2013) aliran keuangan/cash yaitu aliran uang dari pihak produsen/petani ke pihak konsumen atau sebaliknya dari pihak konsumen ke pihak prousen/petani. Aliran keuangan sangat mendominasi mempengaruhi "stock chain" karena berperan dalam proses lancer tidaknya aliran barang.

\section{Aliran Informasi}

Aliran informasi pada rantai pasok komoditas bunga melati putih di Kabupaten Banjar berjalan dua arah, yaitu dari dari hulu ke hilir maupun dari hilir ke hulu. Aliran informasi dapat dikatakan lancar ketika aliran informasi yang terjadi terdapat kemudahan dalam penyampaian dan dapat langsung diterima dengan cepat dan tepat. Menurut Tjipto (2014) yang menyatakan bahwa kriteria aliran informasi yang cepat yaitu adanya ketidak susahan/rintangan dalam tersampaikannya informasi sehingga informasi tersebut dapat cepat tersampaikan. Marjin pemasaran dan share pemasaran pada rantai pasok bunga melati putih di Kabupaten Banjar dapat dilihat padaTabel 2. 
Tabel 2. Nilai Marjin Pemasaran dan Share Pemasaran Bunga melati putih Berdasarkan Pola Distribusi di Kabupaten Banjar dan Efisiensi pemasaran pada rantai pasok bunga melati putih di Kabupaten Banjar

\begin{tabular}{cccc}
\hline \multirow{2}{*}{ No } & \multirow{2}{*}{ Uraian } & $\begin{array}{c}\text { Marjin Pemasaran } \\
(\mathrm{Rp})\end{array}$ & $\begin{array}{c}\text { Share Pemasaran } \\
(\mathrm{Rp})\end{array}$ \\
\hline 1 & Pola 1 & 6.436 & 68,34 \\
2 & Pola 2 & 12.093 & 53,75 \\
3 & Pola 3 & 7.539 & 62,92 \\
\hline
\end{tabular}

Sumber : Data Primer, 2020

Tabel 1 dapat diketahui bahwa pemasaran pada rantai pasok bunga melati putih di Kabupaten Banjar efisien, karena nilai rata - rata share pemasaran yang dihasilkan lebih dari $40 \%$, efisiensi pemasaran terjadi karena nilai share pemasaran yang dihasilkan lebih dari $40 \%$. Menurut Putri et al. (2011) menjelaskan yaitu jika nilai share pemasaran $\geq 40 \%$ maka tataniaga produk masuk kategori"efisien", namun bila angka "share"pemasaran $\leq 40 \%$ masuk kategori tidak efisien. Marjin Pemasaran terbesar ada pada Pola 2 yaitu sebesar 12.093 dan yang terkecil pada Pola 1, sedangkan nilai share pemasaran tertinggi pada Pola 1 yaitu sebesar
68,34. Efisiensi pemasaran terjadi karena nilai marjin pemasaran tidak terlalu besar dan keuntungan yang diambil pedagang relatif kecil. Menurut Muslim dan Darwis (2012) bahwa efisien tidaknya saluran ditentukan dari nilai besar marjin dari sebuah saluran pemasaran dapat diterima oleh produsen (dalam hal ini petani bunga melati) dan total keuntungan yang didapat pedagang oleh relatif lebih kecil atau sedikit dari biaya pemasarannya.

Marjin pemasaran dan share pemasaran pada rantai pasok bunga melati putih di Kecamatan Martapura dan Kecamatan Karang Intan dapat dilihat pada Tabel 3.

Tabel 3. Nilai Marjin Pemasaran dan Share Pemasaran Bunga melati putih Berdasarkan Pola Distribusi di Kecamatan Martapura dan Kecamatan Karang Intan.

\begin{tabular}{cccccc}
\hline \multirow{2}{*}{ No } & Uraian & \multicolumn{2}{c}{ Kecamatan Martapura } & \multicolumn{2}{c}{ Kecamatan Karang Intan } \\
\cline { 3 - 6 } & & $\begin{array}{c}\text { Marjin } \\
\text { Pemasaran } \\
(\mathrm{Rp})\end{array}$ & $\begin{array}{c}\text { Share } \\
\text { Pemasaran } \\
(\%)\end{array}$ & $\begin{array}{c}\text { Marjin } \\
\text { Pemasaran } \\
(\mathrm{Rp})\end{array}$ & $\begin{array}{c}\text { Share } \\
\text { Pemasaran } \\
(\%)\end{array}$ \\
\hline 1 & Pola 1 & 6.237 & 65,87 & 6.822 & 69,88 \\
2 & Pola 2 & 12.462 & 51,82 & 13.582 & 55,62 \\
3 & Pola 3 & 7.227 & 61,25 & 7.631 & 63,97 \\
\hline
\end{tabular}

Sumber: Data Primer, 2020

Tabel 3 menjelaskan bahwa pola rantai pasok bunga melati putih di Kecamatan Martapura dan Kecamatan Karang Intan adalah pola 1, pola 2 dan pola 3,. Nilai marjin pemasaran dan share pemasaran di Kecamatan Martapura terbesar adalah Rp 12.462 dan 65,87\%. Nilai dari marjin pemasaran dan share pemasaran Kecamatan Karang Intan berturut turut adalah $\mathrm{Rp} 13.582$ dan $69,88 \%$. Independent sample t-test hasil uji bedanya pada marjin pemasaran didapatkan nilai yaitu Sig. 2 tailed yaitu bernilai 0,246. Independent sample $t$ test uji beda pada share pemasaran bernilai Sig. 2 tailed yaitu 0,221. Nilai 0,221 yang ternyata angkanya >0,05, sehingga dapat disimpulkan bahwa efisiensi 
pemasaran antara Kecamatan Martapura dan Kecamatan Banjar tidak.

Hasil yang telah diperoleh yaitu tidak terdapat perbedaan yang signifikan karena kedua kecamatan merupakan sentra utama komoditas bunga melati putih di Kabupaten Banjar sehingga luas lahan dan jumlah petani melati putih banyak. Jumlah petani yang banyak membuat kelompok tani lebih hidup dan dapat saling berkoordinasi. Selain luas lahan dan jumlah petani, lembaga pemasaran atau pedagang di kedua kecamatan juga banyak, sehingga pelaku rantai pasok lebih lengkap. Pemasaran dapat langsung dilakukan dengan jarak yang terjangkau atau dekat dengan wilayah tersebut dan biaya yang harus dikeluarkan untuk pemasaran relatif lebih sedikit. arjin pemasaran dan share pemasaran di Kecamatan Martapura dan Kecamatan Karang Intan dapat mengadakan pembagian keuntungan yang adil sehingga dikategorikan efisien. Menurut Istiyanti (2010) bahwa efisensi tataniaga pemasaran bila arus hasil bisa diterima oleh produsen dan harga yang dikeluarkan oleh pihak konsumen produk tersebut. Syarat tumbuhnya tanaman melati putih akan tumbuh baik dan optimal jika dibudidayakan pada tanah Podzolik Merah Kuning (PMK), Latosol, dan Andosol dengan tekstur sedikit berpasir-liat yang mengandung sumber hara makro organik. Untuk membudidayakan bunga melati putih disyaratkan tanah yang remah, porus, berpasir, dan banyak unsur hara. Pupuk daun digunakan untuk peningkatan produksi melati putih, yaitu pupuk yang banyak mengandung unsur fosfor $(\mathrm{P})$, yaitu jenis pupuk Gandasil B (6-2030) atau Hyponex biru (10-4015) dengan waktu yang dianjurkan saat pagi hari ("pukul 09.00") dan sore hari (pukul 15.30 - 16.30) atau ketika matahari sudah teduh (Setyawati, 2009).

Proses Ekstensifikasi dan

Intensifikasi Tanaman melati putih burneh telah dilakukan oleh petani di
Desa Tunjung Kecamatan Buneh. Budidaya melati sejak pengolahan lahan sampai pasca panen telah mereka lakukan, namun masih terdapat permasalahan yaitu harga bunga melati yang tidak bisa diprediksi dari harga $\mathrm{Rp}$. 15.000 sampai Rp. 25.000. Kisaran harga yang cukup jauh tersebut membuat warga Desa Tunjung lebih melakukan kegiatan agribisnis agar harga bunga melati tidak anjlok diwaktu panen sehingga kesejahteraan warga meningkat yaitu menambah nilai jual melati dengan merangkai bunga melati melalui peranan wanita tani (Mardiyah Hayati dan Teti Sugiarti, 2009).

Volume produksi kembang melati putih yang dapat terserap di tingkat pedagang pengecer di Pasar Martapura sekitar 18,50 kg/bulan/ha. Periode penjualan di tingkat pedagang pengecer rata-rata dua hari dengan perlakuan penyimpangan dan penyegaran. Harga pembelian langsung oleh pengecer per $\mathrm{kg}$ lebih murah dibanding harga pembelian di tingkat pedagang pengumpul, yaaitu $\mathrm{Rp}$ $2.350 / \mathrm{kg}$, hal ini karena pedagang pengecer mendapat pasokan dari luar petani yang terlambat mengantar bunga pada pedagang pengumpul. Pedagang pengecer dipasarpasar Banjarmasin rata-rata mampu menyerap bunga melati putih sebanyak $50,19 \mathrm{~kg} / \mathrm{bulan}$. Terdiri atas volume penjualan sebesar $44,79 \mathrm{~kg} / \mathrm{bulan}$ dan susut $5,40 \mathrm{~kg} / \mathrm{bulan}$. Harga beli rata-rata $\mathrm{Rp}$ 5.221,15 dan harga jual rata-rata $\mathrm{Rp}$ $11.326,92 \mathrm{~kg}$. Biaya pemasaran besar dan pasokan bunga melati putih yang sedikit dibandingkan dengan jumlah yang diinginkan oleh konsumen merupakan faktor yang menyebabkan tingginya harga jual tersebut. Pengrajin kembang pengantin rata-rata memerlukan bunga melati putih sebanyak 45,29 kg/bulan. Periode penjualan yang dilakukan pengrajin kembang pengantin tergantung pada adanya pemesanan, rata-rata pada hari Minggu. Untuk membuat satu set kembang 
pengantin memerlukan $0,67 \mathrm{~kg}$ bunga melati putih, dengan harga beli sebesar Rp $3.750 / \mathrm{kg}$ dan harga jual sekitar $\mathrm{Rp}$ $16.949,40 / \mathrm{kg}$ (E. Hardiati dan S. Suwasono, 2006). Melati putih (Jasminum sambac) adalah bunga yang selain beraroma harum dan meiliki banyak kegunaan, manfaat melati masih banyak dimanfaatkan hanya untuk tanaman hias, diambil bunganya pada proses perkawinan dan pembuatan teh melati ternyata melati juga bias sebagai tanaman obat seperti sesak nafas, demam dan sakit kepala karena mengandung"indol,"benzyl, "livalyacetat"dengan perlakuan khusus penamanan melati menggunakan media pupuk, tanah kebun dan sekam padi dengan perbandingan 1:1:1 dan disertai pemberian"paclobutrazol"(Novi Rizky 2014).

Pelaku rantai pasok bunga melati putih di Kabupaten Batang meliputi petani, pengepul, pedagang besar dan pengecer. Aliran produk pada rantai pasok bunga melati putih bergerak dari petani sampai kepada konsumen, Pemasaran pada rantai pasok bunga melati putih di Kabupaten Batang efisien, karena nilai rata - rata share pemasaran yang dihasilkan adalah $50,9 \%$ dan nilai rata - rata marjin pemasaran yang dihasilkan adalah $\mathrm{Rp}$ 41.451. Nilai rata - rata dari marjin pemasaran dan share pemasaran Kecamatan Martapura dan Kecamatan Batang berturut turut adalah Rp 18.939 dan $61,3 \%$ serta $\mathrm{Rp}$ 52.844 dan 41,6\%, (Rizal Muttaqin, Titik Ekowati, Mukson, 2019). Melati dari dahulu sudah dibudidayakan di Indonesia sebagai bahan ritual adat istiadat, keagamaan dan lain sebagainya sehingga dinobatkan bunga melati sebagai "puspa bangsa" Indonesia pada bulan Juni 1990. Cocok ditanam di semua lahan namun lebih cocok pada lahan gembur dan pencahayaan matahari yang cukup banyak dan beriklim tropis dan berkelembaban tinggi (Ari Handriatni, 2008).

Efisiensi rantai pasok pada hasil produksi KWT Melati metrik TSMC bernilai 14,23 persen dengan kinerja actual berentang jauh dengan target minimal kerja ("Parity") di bidang indutri yang berpengaruh terhadap manajemen rantai pemasaran dan bernilai "rating" dua pada strategi pengembangan metrik (Sartika Lestari, Zainal Abidin, Suarno Sadar, 2016).

Penelitian menggunakan rancangan acak kelompok dengan 2 faktor yaitu jenis pelarut dan lama ekstraksi. Masing-masing faktor terdiri dari 3 level dan 2 level dengan 3 kali ulangan, sehingga didapatkan total 18 satuan percobaan. Pelarut yang digunakan yaitu petroleum eter dan heksan. Lama ekstraksi yang digunakan yaitu 3 jam, 4 jam, dan 5 jam. Hasil penelitian diperoleh rendemen yang dihasilkan menggunakan pelarut petroleum eter dan pelarut heksan berbeda nyata. (Nur Hidayat, ika Atsari Dewi dan Danis Alfiana Hardani, 2015).

Melati putih (Jasminum sambac (L) W. Ait.) adalah tanaman yang banyak digunakan hanya dimanfaatkan aroma harumnya saja padahal melati dan digunakan sebagai tanaman obat, bahkan kini banyak digunakan sebagai bahan baku pabrik minyak wangi, penambah rasa melati pada teh dan lain sebagainya. Dibudidayakan menggunakan stek batang walau bunga melati agak lambat pertumbuhan akarnya (Retno Catur Wulandari, Riza Linda, Mukarlina, 2013)

\section{KESIMPULAN DAN SARAN}

\section{Kesimpulan}

Berdasarkan penilitian rantai pasok bunga melati putih

di Kabupaten Banjar dapat ditarik

kesimpulan sebagai berikut :

1. Prospek Aliran produk pada rantai pasok bunga melati putih bergerak dari petani sampai kepada konsumen, kemudian aliran keuangan pada rantai pasok bunga melati putih bergerak dari konsumen menuju ke petani.

2. Pola rantai pasok bunga melati putih di Kecamatan Martapura dan 
Kecamatan Karang Intan adalah pola 1, pola 2 dan pola 3 ,. Nilai marjin pemasaran dan share pemasaran di Kecamatan Martapura terbesar adalah Rp 12.462 dan 65,87\%. Nilai dari marjin pemasaran dan share pemasaran Kecamatan Karang Intan berturut turut adalah Rp 13.582 dan 69,88\%. Hasil uji beda Independent sample t-test pada marjin pemasaran didapatkan hasil sebesar 0,246. Hasil uji beda Independent sample t-test pada share pemasaran didapatkan sebesar 0,221. Hasil tersebut menunjukkan angka $>0,05$, sehingga dapat disimpulkan bahwa tidak terdapat perbedaan yang signifikan dari efisiensi pemasaran antara Kecamatan Martapura dan Kecamatan Banjar.

\section{Saran}

Sebaiknya petani melakukan pembukuan penjualan dan pembelian dan perlu dikelola dengan manajemen yang baik sehingga memiliki data atau arsip yang lengkap dan dapat digunakan sewaktu waktu apabila diperlukan. Gabungan kelompok tani harus segera dimanfaatkan dengan maksimal agar dalam penjualan petani mempunyai nilai tawar yangtinggi.

\section{DAFTAR PUSTAKA}

Ari Handriatni, 2008. Budidaya Tanaman Melati Di Wilayah Pesisi r Dengan Bahan Organik Sarana Pembelajaran Ekologi. Jurnal Cakwarala Pendidikan Vol.27 Nomor 01 Februari 2008. LPPMP Universitas Negeri Yogyakarta (UNY).

BPS. 2020. Kabupaten Banjar Dalam Angka 2019. BPS Martapura

Daniel, Moehar. 2002. Pengantar Ekono mi Pertanian. Cetakan Pertama. Jakarta: Bumi Aksara
E. Hardiati dan S. Suwasono, 2006. Tataniaga Bunga Melati Di Desa Labuan Tabu

Kecamatan Martapura Kabupaten Banjar. Jurnal Buana Sains Volume 6 Nomor 2. Fakultas Pertanian Universitas Tribhuana Tunggadewi. Malang.

Hanafiah, dan Saefuddin. 2011.

Tataniaga Hasil Perikanan. Jakarta : Universitas Indonesia.

Istiyanti,E. 2010. Efisiensi Pemasaran Cabai Merah Keriting di Kecamatan Ngemplak Kabupaten Sleman. J. Pertanian MAPETA. 12: 72-144.

Kotler,Philip dan Kevin Lane Keller, 2008. Manajemen Pemasaran. Edisi duabelas. Jakarta: Macanan Jaya Cemerlang.

Mardiyah Hayati dan Teti Sugiarti, 2009. Prospek Agribisnis Tanam an Melati putih dan Peran Wanita Madura. Jurnal Embryo Volume 6 Nomor 1 Juni

Muslim, C dan V. Darwis. 2012. Keragaan, farmer share dan efisiensi kedelai di Kabupaten Cianjur. J. SEPA. 9 (1): $1-11$.

Novi Rizky 2014. Induksi Pemekaran Bunga Tanaman Melati putih Putih Dengan Pemberian Beberapa Paclobutrazol Pada Beberapa Konsentrasi. Jurnal Pelangi Vol.3 No.2 STIKIP-PGRI Sumatera Barat.

Nur Hidayat,Ika Atsari Dewi dan Danis Alfiana Hardani, 2015. Ekstraksi Minyak Melati (Kajian Teknis Pelarut dan Lama Ekstraksi). Jurnal Industria : Jurnal teknologi dan Manajemen Agroindustri Volume 4 
Nomor $22015 . \quad$ Universitas Brawijaya Malang

Putri, Y. R., I. Santoso dan W. Roessali. 2014. Farmer sha re dan efisiensi saluran pemasaran kacang hijau (Vigna Radiate, L.) di Kecamatan Godong Kabupaten Grobogan. J. Agriwiralodra. 6: 28-34.

Renaldi, E., T. Karyani., A. H. Sadeli dan H. N. Utami. 2013. Model pembiayaan pra panen pada rantai pasok agribisni $\mathrm{s}$ berdasarkan sistem produksi komoditas cabai merah dengan o rientasi pasar terstruktur. J. Sosiohumaniora. 15:253-260.

Retno Catur Wulandari, Riza Linda, Mukarlina, 2013. Pertumbuhan Stek Melati Putih Dengan Peemberian Air Kelapa dan IBA (Indole Butyric Acid). Jurnal Protobiont Volume 2 Nomor 2 Tahun 2013. Universitas Tanjung Pura Pontianak

Rizal Muttaqin, Titik Ekowati, Mukson, 2019.Analisis Rantai Pasok Bung a melati di Kabupaten Batang. Jurnal Agromedia Volume 37 Nomor 2 September 2019. Fakultas Peternakan dan Pertanian Universitas Diponegoro Semarang.
Sartika Lestari, Zainal Abidin, Suarno Sadar, 2016. Analisis Kinerja Rantai Pasok Dan Nilai Tambah Produk Olahan KWT Melati Di Desa Tribudisyukur Kecamatan Kebun Tebu Lampung Barat. Jurnal JIIA Volume 4 Nomor 1 Januari 2016. Fakultas Pertanian Universitas Lampung.

Setyawati 2009. Budidaya Tanaman Melati putih. Jurnal Iptek Hortikultura Volume 7 Nomor 1 Tahun 2009. Balai Penelitian Tanaman Hias Cianjur Jawa Barat

Soekartawi. 2002. Prinsip Dasar Manajemen Pemasaran Hasilhasil Pertanian. Jakarta: PT. Raja Grafindo.

Tjipto, A. I. 2014. Analisis Kinerja Pemasok Pada Manajemen Ranta i Pasokan Perusahaan Jasa Konstruksi. J. Manajemen.

Widisatriani, Widyantara dan I . G. A. L. Angreni. 2015.Manajemen Rantai Pasok Benih Cabai Rawit Di Desa Batuan Kaler Kecamatan Sukawati , Kabupaten Gianyar. J. Agribisnis dan Agrowisata. 4: 289 297. 